\section{THU0019 INTRACELLULAR EXPRESSION OF CXCR3 ON RHEUMATOID ARTHRITIS SYNOVIAL TISSUE CELLS}

${ }^{1} \mathrm{O}$ Krystufkova, 'J Vencovsky, 'S Ruzickova, 'J Sinkora, 'Z Rehakova, 'f Niederlova, ${ }^{3} \mathrm{CA}$ Power, ${ }^{3} \mathrm{C}$ Plater-Zyberk. ${ }^{1}$ Clinical Department, Institute Rheumatology, Praha 2; ${ }^{2}$ Department Gnotobiology, Institute Microbiology AV CR, Novy Hradek, Czech Republic; ${ }^{3}$ Immunology Department, SPRI, Geneva, Switzerland

\subsection{6/annrheumdis-2001.528}

Background Inflammatory cell infiltration and synovial activation are important processes in rheumatoid arthritis. Chemotactic gradients of various chemokines are responsible for cell attraction and possibly for their activation. We have previously detected strong expression of chemokine receptor CXCR3 in the rheumatoid joint by immunostaining.

Objectives Characterisation of the cells expressing CXCR3 in RA synovial membrane.

Methods Synovial tissue samples were obtained from RA patients undergoing either synovectomy or a total joint replacement. Cells were released by digestion with collagenase, DNAse and briefly with hyaluronidase. A three colour fluorescence analysis was performed with FITC conjugated anti-CXCR3 mouse MAb (R\&D) and with a panel of phycoerythrin (PE) conjugated MAb (anti-CD3, CD4, CD8, CD19, CD55, CD31, CD68, CD14 and CD45). Live cells were identified by propidium iodide. PBCs were stained using the same protocol.

Results As expected, a proportion of $\mathrm{CD}^{+}$and $\mathrm{CD}^{+}$blood and synovial cells was CXCR3 positive. In addition, CXCR3 was also seen in synovial cells positive for CD55, CD14, CD8 and to a less extent CD31. However, in contrast to the surface staining of cells from peripheral blood, CXCR3 staining was identified only intracellularly in synovial cells. No CXCR3 staining could be detected on the surface of any type of viable synovial cell, including CD3 positive lymphocytes.

Conclusion Flow cytometry identifies synovial cells that display intracellular CXCR3 staining. These cells are comprised of $\mathrm{T}$ lymphocytes, macrophages, possibly synovial fibroblasts and endothelial cell populations. The intracellular presence of CXCR3 suggests a possible internalisation of this molecule, which may be a consequence of ligand binding. The significance of this phenomenon and of CXCR3 expression in cell types other than leukocytes remains to be determined.

This work was supported by a grant NI/6459 from IGA MZ CR.

\section{THU0020 ROLE OF FCGAMMARII AND FCGAMMARIII IN INFLAMMATION AND CARTILAGE DAMAGE DURING MURINE EXPERIMENTAL ANTIGEN-INDUCED ARTHRITIS}

${ }^{1} \mathrm{PL}$ Van Lent, ${ }^{1} \mathrm{KC}$ Nabbe, ${ }^{1} \mathrm{AB}$ Blom, ${ }^{1} \mathrm{AE}$ Holthuysen, ${ }^{1} \mathrm{LB}$ Van de Putte, ${ }^{2} \mathrm{~S}$ Verbeek, ${ }^{1}$ WB Van den Berg. ${ }^{1}$ Rheumatology, University Medical Centre Nijmegen, Nijmegen, The Netherlands; ${ }^{2}$ Human and Clinical Genetics, University Medical Centre Leiden, Leiden, The Netherlands

\subsection{6/annrheumdis-2001.529}

Background IgG-containing immune complexes, which are found in most RA joints, communicate with haematopoietic cells using three classes of $\mathrm{Fc}$ receptors (Fc $\gamma \mathrm{RI}$, II, III). In a previous study we found that if an experimental arthritis was elicited in knee joints of FcR $\gamma$-chain deficient mice which lack functional $\mathrm{Fc} \gamma \mathrm{RI}$ and III, joint inflammation was lower and severe cartilage destruction was absent.
Objectives To examine the role of FcyRII and III in inflammation and functional cartilage damage in knee joints with chronic experimental antigen-induced arthritis (AIA) using Fc $\gamma$ RIII and Fc $\gamma$ RII deficient mice.

Methods FcyRII and FcyRIII -/- mice and their controls were immunised with methylated BSA in complete adjuvant followed by induction of arthritis by local injection of mBSA into the right knee joint. The course of inflammation was studied by $99 \mathrm{mTc}$ uptake. Chronic inflammation and cartilage damage (depletion of proteoglycans, chondrocyte death and matrix erosion) was studied histologically in total knee joints sections stained with haematoxylin or safranin-O. Aggrecan breakdown in cartilage caused by metalloproteinases (MMP) was studied by immunolocalisation (VDIPEN neoepitopes) and image analysis.

Results Three weeks after immunisation both humoral (total IgG, IgG1, IgG2a and IgG2b levels) and cellular (T cell responses as measured by lymphocyte proliferation) immunity raised against mBSA was comparable in all groups examined. IgG2a levels were comparable in Fc $\gamma$ RIII-/- but higher in Fc $\gamma$ RII-/- if compared to controls. Joint swelling at day 1, 3 and 7 was similar in FcyRIII -/- mice and significantly (103\%) higher in Fc $\gamma$ RII-/- on day 1 but not on later time-points. Histologically, at day 7 after AIA induction, exudate and infiltrate in the knee joint was similar in FcyRIII -/- and significantly higher (100\% and 388\%) in FcyRII-/- mice if compared to controls. MMPinduced neoepitopes determined in various cartilage layers (tibia and femur) were comparable in FcyRIII-/- and higher (respectively $155-360 \%$ and $67-75 \%)$ in FcyRII-/-. Initial depletion of proteoglycans was similar (40-70\%) in all groups. In the chronic phase, chondrocyte and cartilage matrix erosion in tibia and femur stage was significantly elevated in FcyRII -/- but not in Fc $\gamma$ RIII-/- mice.

Conclusion FcyRIII is redundant or not involved in the presence of Fc $\gamma$ RI whereas Fc $\gamma$ RII is a crucial inhibiting factor in acute and chronic inflammation and cartilage erosion during antigeninduced arthritis.

\section{REFERENCE}

1 Van Lent, et al. Arthritis Rheum. 2000;43(4):740-52

\section{THU0021 DEFECTIVE RAP1 ACTIVATION IN SYNOVIAL FLUID T LYMPHOCYTES FROM PATIENTS WITH RHEUMATOID ARTHRITIS}

${ }^{1} \mathrm{PH}$ Remans, ${ }^{2} \mathrm{KA}$ Reedquist, ${ }^{1} \mathrm{SI}$ Gringhuis, ${ }^{1} \mathrm{FC}$ Breedveld, ${ }^{1} \mathrm{JM}$ Van laar, ${ }^{1} \mathrm{CL}$ Verweij. ${ }^{1}$ Rheumatology, Leiden University Medical Center, Leiden, The Netherlands; ${ }^{2}$ Laboratory for Physical Chemistry, Center for Biomedical Genetics, University Medical Center, Utrecht, The Netherlands

\subsection{6/annrheumdis-2001.530}

Background Rap1 is a small G-protein, member of the Ras GTPase family. Rap1 has been linked to T cell anergy and it is suggested that Rap1 has the potential to inhibit Ras-mediated oncogenic or growth promoting activity. Synovial fluid (SF) T cells from patients with rheumatoid arthritis (RA) display a defective phosphorylation pattern of several pivotal signalling proteins and severe hyporesponsiveness upon antigenic stimulation. Our previous data showed that the hyporesponsive state of the SF T cells in RA correlates with markers of oxidative stress and replenishment of the intracellular level of the anti-oxidant (GSH) by treatment of cells with $\mathrm{N}$-acetyl-cysteine (NAC) seems to partly restore the observed signalling defects. 
Objectives To determine Rap1 activation and its correlation with oxidative stress in $\mathrm{T}$ cells from healthy controls compared to peripheral blood $(\mathrm{PB})$ and SF $\mathrm{T}$ cells isolated from patients with RA.

Methods T cells from healthy donors and PB and SF from RA patients were isolated and $5 \mathrm{~min}$ after stimulation with either CD3 antibodies or PMA+ionomycine, whole cell lysates were prepared in Ral lysis buffer. GTP-bound Rap1 was precipitated using the bacterial expressed fusion protein GST-RalGDS and detected by ECL Western blotting. In whole cell lysates, total Rap1, RapGAP and Spa1 were detected by ECL western blotting as well.

Results Our data show that in T cells isolated from healthy controls, Rap1 activation was sensitive to redox balance alterations. Upregulation of intracellular GSH by incubation with $10 \mathrm{mM}$ NAC for $48 \mathrm{~h}$ resulted in diminished Rap1 activation, while depletion of GSH by pre-incubation with $200 \mathrm{mM}$ BSO resulted in increased Rap1 activation. We also observed that treatment of T cells with $\mathrm{H} 2 \mathrm{O} 2$ led to the rapid activation of Rap1.

Despite an environment of oxidative stress in the inflamed joints of RA patients, we found that in SF T cells Rap1 was present in its inactive GDP-bound state. Furthermore, while the PB T cells of RA patients could be normally activated, Rap1 remained inactive in SF T cells upon stimulation. The defective Rap1 activation was not due to increased levels of the Rap1 GTPase activating proteins RapGAP or spa1. While restoration of the intracellular redox balance seems to reverse the hypo responsiveness of the SF T cells, this had no effect on the defective rap1 activation.

\section{Conclusion}

- Rap1 activation is defective in SF T cells from RA patients, and cannot be restored by the replenishment of GSH with NAC.

- This defective activation is not due to increased levels of the Rap1 GTPase activating proteins RapGAP or Spa1.

\section{THU0022 KIR3DL1 (NKB1) AND CD94 EXPRESSION ON PERIPHERAL BLOOD T CELLS, NK CELLS AND NKT CELLS IN BEHCET'S DISEASE}

${ }^{1} \mathrm{G}$ Saruhan Direskeneli, ${ }^{1} \mathrm{FA}$ Uyar, ${ }^{2} \mathrm{~A}$ Cefle, ${ }^{2} \mathrm{~S}$ Celebi Onder, ${ }^{2} \mathrm{M}$ Inanc, ${ }^{2} \mathrm{~L}$ Ocal, ${ }^{2} \mathrm{~A}$ Gul. ${ }^{1}$ Department of Physiology; ${ }^{2}$ Department of Internal Medicine, Division of Rheumatology, Istanbul Faculty of Medicine, University of Istanbul, Istanbul, Turkey

\subsection{6/annrheumdis-2001.531}

Background Behcet's disease (BD) is strongly associated with HLA-B51. However, the role of HLA-B51 in the pathogenesis still remains to be elucidated. We have recently identified a weak association of HLA-B*2702 with BD. HLA-B51 and B*2702 shares one of the $5 \mathrm{Bw} 4$ motifs at positions 77-83, which interacts with a group of recently described receptors on mainly NK cells, but also $\mathrm{CD}^{+}$and gamma-delta $\mathrm{T}$ cells. Interaction of HLA-B molecules with one of these receptors, killer immunoglobulin-like receptor (KIR) on NK, NKT, $\mathrm{CD} 8^{+}$and/or gamma/ delta $\mathrm{T}$ cells may be one of the pathogenic mechanisms involved in BD.

Objectives We aimed to investigate the KIR3DL1 and CD94 (a C-type lectin receptor which mainly interacts with HLA-E) expression in BD.

Methods The study group consisted of 51 patients, who fulfil the International Study Group Criteria, and 32 HLA-Bw4 motif matched healthy controls. All patients and controls were already HLA-typed, and they were selected and grouped according to the presence and number of the shared Bw4 epitope. All of the patients were receiving treatment and their disease activity was under control. Expression patterns of CD3, CD16, CD56, CD45, CD14, KIR3DL1 (NKB1) and CD94 in peripheral blood leukocytes were determined with fluorescent-labelled monoclonal antibodies using flow cytometry.

Results The percentage of $\mathrm{CD} 3^{+}$cells was found to be increased in BD patients, but there was no significant difference in NK $\left(\mathrm{CD} 56^{+} / \mathrm{CD} 16^{+}, \mathrm{CD} 3-/ \mathrm{CD} 56^{+}\right)$and NKT $\left(\mathrm{CD} 3^{+} / \mathrm{CD} 56^{+}\right)$cells between BD patients and controls. The distribution of KIR3DL1 receptor did not show any significant difference in patients, however we observed a significant increase of CD94 expression in T cells, NK and NKT cells. Subgroup analysis in patients carrying 1, 2 or no copies of the shared Bw4 motif also did not reveal any effect on the expression of KIR3DL1 and CD94.

Conclusion We did not observe any difference in the expression of KIR3DL1 receptors in this group of BD patients compared with healthy HLA-Bw4 motif matched controls. Increased CD94 expression in peripheral blood T cells, NK and NKT cells of BD patients needs to be confirmed and analysed further.

This study was supported by the Research Fund of the University of Istanbul (1076).

\section{THU0023 ANTIGEN INDEPENDENT GENERATION OF IMMUNO- MODULATORY TH2 CELLS IS REGULATED BY MAP KINASE ACTIVATION AND IL-4}

${ }^{1} \mathrm{~A}$ Skapenko, ${ }^{2} \mathrm{PE}$ Lipsky, 'JR Kalden, ${ }^{1} \mathrm{H}$ Schulze-Koops. 'Department of Internal Medicine III, University Erlangen-Nuremberg, Erlangen, Germany; ${ }^{2}$ NIAMS, NIH, Bethesda, USA

10.1136/annrheumdis-2001.532

Background Evidence suggests that human autoimmune diseases might be driven by pro-inflammatory Th1 cells whereas immuno-modulatory Th2 cells are rarely found. The mechanisms regulating Th2 cell differentiation from resting human $\mathrm{T}$ cells, however, are not completely characterised.

Objectives To delineate the mechanisms controlling Th2 differentiation, we defined optimal Th2 inducing conditions in human naive and memory $\mathrm{CD} 4^{\text {pos }} \mathrm{T}$ cells in vitro and investigated activation of intracellular signalling pathways and their individual role in Th2 differentiation.

Methods A cell culture system was employed that permitted Th2 cell differentiation after short term priming. The phenotype of freshly isolated and primed T cells was determined by cytometric analysis of intracellular cytokines. Activation of intracellular signalling pathways was assessed by western blot analysis or kinase activity assays.

Results In the absence of TCR ligation, stimulation of CD28 induced Th2 differentiation from purified $\mathrm{CD} 4^{\text {pos }}$ peripheral blood memory but not from cord blood naive T cells. Co-stimulation via CD28 and the TCR, on the other hand, enhanced Th2 cell differentiation from naive $\mathrm{T}$ cells but suppressed it from memory $\mathrm{T}$ cells. Comparison of naive and memory $\mathrm{T}$ cell responses to $\mathrm{CD} 28$ stimulation, therefore, revealed critical signals facilitating Th2 cell differentiation. CD28 engagement initiated IL-4 gene transcription and activation of p38 MAP kinase in memory T cells but not in naive cells. By contrast, PI3-kinase and JNK/SAPK pathways were activated in both subsets. Whereas IL-4 had a synergistic effect with anti-CD28 on the generation of Th2 cells in memory $\mathrm{T}$ cells, it was not sufficient to complement CD28 signals in naive $\mathrm{T}$ cells. $\mathrm{T}$ cell differentiation in the presence of specific inhibitors to IL-4, the MAP 